\title{
VOTING MACHINES AND VOTER PARTICIPATION IN FOUR MICHIGAN CONSTITUTIONAL REVISION REFERENDA
}

\author{
Norman C. Thomas \\ University of Michigan
}

$\mathrm{T}$ HE ANALYSIS of voting and elections has undoubtedly become one of the principal areas of investigation for political scientists, especially among those primarily concerned with American politics. Quite understandably, much of the research on the subject has tended to focus on individual voting behavior and its relationship to psychological and sociological variables. ${ }^{1}$ This research has provided important insights into one of the most fundamental phenomena of democratic politics and undoubtedly further contributions to our understanding of voter choice are forthcoming. There is, however, at least one aspect of American electoral behavior which has not been as thoroughly investigated. The effect of the mechanics of the ballot may not be as intellectually fascinating a topic as, say, the psychological determinants of voting choice, but it nevertheless can have an impact on election results.

Studies of the mechanical aspects of the electoral system have dealt primarily with two phenomena: ballot form, i.e., the arrangement of candidates' names on the ballot by either party column or office blocks; and the use of either voting machines or paper ballots as the vehicle for the expression of voter choice. We know, as a result of the Survey Research Center studies of the 1952 and 1956 presidential elections, that ballot form has less impact on straight-ticket voting among strong party identifiers than among weak party identifiers. ${ }^{2}$ In addition, Jack L. Walker has shown in a recent study that ballot form has a significant effect on voter participation in partisan contests for lower offices. ${ }^{3}$ Walker found that states using the party column ballot exhibited consistently less "roll-off" than states

Noте: Research for this paper was aided by a grant from the Horace H. Rackham School of Graduate Studies of the University of Michigan to the Department of Political Science for a study of the politics of constitutional revision referenda in Michigan between 1958 and 1963. I am especially indebted to J. Merrill Shanks of the Survey Research Center who guided me in analyzing the data. Responsibility for what is said here is, however, mine alone.

${ }^{1}$ Some of the better-known works include: Paul F. Lazarsfeld, Bernard Berelson, and Hazel Gaudet, The People's Choice (New York: Columbia U. Press, 1948) ; Bernard Berelson, Paul F. Lazarsfeld, and William McPhee, Voting (Chicago: U. of Chicago Press, 1954); Angus Campbell, Gerald Guerin, and Warren E. Miller, The Voter Decides (Evanston: Row, Peterson, 1954) ; Angus Campbell, Phillip E. Converse, Warren E. Miller, and Donald E. Stokes, The American Voter (New York: Wiley, 1960); and by the same authors, Elections and the Political Order (New York: Wiley, 1966).

${ }^{2}$ See Angus Campbell and Warren E. Miller, "The Motivational Basis of Straight and Split Ticket Voting," American Political Science Review, 51 (1957), 293-312. They found that straight ticket voting did not vary with ballot form among voters manifesting a high level of party identification. On the other hand, voters having a low level of party identification tended to vote straight tickets more frequently under single-choice or party column ballots than under multiple-choice or office block ballots; see p. 307 . See also, The American Voter, pp. 275-76 and 285-86.

${ }^{3}$ See J. L. Walker, "Ballot Forms and Voter Fatigue: An analysis of the Office Block and Party Column Ballots," Midwest Journal of Political Science, 10 (1966), 448-63. 
employing the office block ballot. That is, party column states manifested a smaller drop in participation from contests for the highest office to contests for lower offices.

For some time, students of referendum elections have observed the roll-off effect. ${ }^{4}$ These earlier studies noted that referendum elections almost invariably attracted fewer voters than contests for public office held at the same time. Two more recent studies have concluded that the use of voting machines rather than paper ballots also contributes to roll-off in referendum elections. ${ }^{5}$ In his analysis of a 1958 Michigan referendum on the question of calling a state constitutional convention, White examined the vote cast by county and reached the conclusion that voting machines were "an important factor in producing the low rate of participation in the referendum." Because the referendum had to obtain a majority of the votes cast in the election, a figure determined by the total vote for governor, the roll-off was an especially critical factor in the defeat of the proposal to call a convention. White also reasoned that since the use of voting machines tended to be concentrated in urban areas, the voice of those areas was weakened by their use of voting machines while rural areas continued largely to use paper ballots.

In an Iowa study, Mather employed a somewhat different approach. Using the county as the unit of analysis, he examined the effect of machine and paper ballot voting on participation levels in sixteen referendum elections between 1920 and 1960. Defining participation level as the ratio of the total votes cast in the referendum to "the total votes cast for all candidates for the office for which the most votes were cast," " Mather found that the use of voting machines rather than paper ballots resulted in substantially lower participation. Although he noted a rather weak tendency for a higher participation level to be associated with a negative vote on the referendum, Mather concluded it offered no basis for prediction. In a 1960 constitutional convention referendum, an issue on which the Iowa electorate divided on a sharp urban-rural cleavage, Mather found a high correlation between urbanism and support for constitutional revision. The all-machine ballot counties, which were more urbanized, favored the convention while the all-paper ballot counties, which were heavily rural, opposed it. Participation in the paper ballot counties, however, was at a much higher level. This led Mather to conclude, as White had in his Michigan study, that a uniform ballot, either all machine or all paper, would have considerably narrowed the margin of defeat for the convention proposal. ${ }^{8}$

Both White and Mather, then, have found that the use of voting machines rather than paper ballots results in lower participation levels in referendum elec-

\footnotetext{
"See John A. Fairlie, "The Referendum and Initiative in Michigan"" The Annals, 43 (1912), 146-58; James K. Pollock, The Initiative and Referendum in Michigan (Ann Arbor: U. of Michigan Press, 1940), pp. $56 \mathrm{ff}$; V. O. Key and W. W. Grouch, The Initiative and Referendum in California (Berkeley: U. of California Press, 1939), pp. 537-38; and Joseph G. LaPalombara, The Initiative and Referendum in Oregon: 1938-1948 (Corvallis: Oregon State U. Press, 1950), p. 97.

${ }^{5}$ John P. White, Voting Machines and the 1958 Defeat of Constitutional Revision in Michigan (Ann Arbor: Institute of Public Administration, U. of Michigan, 1960); and, George B. Mather, Effects of the Use of Voting Machines on Total Votes Cast: Iowa - 1920-1960 (Iowa City: Institute of Public Affairs, U. of Iowa, 1964).
}

- White, ibid., p. 37.

"Mather, ibid., p. 40.

${ }^{8}$ Ibid., pp. 53-55. 
tions. They attribute this phenomenon to the placement of referendum questions on a machine ballot in a less prominent position relative to partisan contests for office and not to any inherent difficulty in voting on a machine per se. That is, it is more difficult for the voter to cast his vote on a referendum question when it is placed, say, at the side or bottom of a voting machine which displays contests for elective office in a more central location than when he must mark separate paper ballots containing the various contests and referenda. Both scholars also suggest that this phenomenon tends to give areas which use paper ballots an advantage over machine ballot areas. Since rural areas tend to use paper ballots and urban areas tend to be more extensively mechanized, the former presumably enjoy an advantage over the latter in referendum elections. Mather's study of a series of referenda did not uncover a strong relationship between ballot mechanism and the direction of the vote. However, both he and White concluded that the use of voting machines in more urbanized areas and paper ballots in rural areas worked against the passage of referendum proposals to call constitutional conventions in Michigan (1958) and Iowa (1960).

The three constitutional revision referenda which Michigan held subsequent to 1958 offer an opportunity to examine further the effect of the use of voting machines and paper ballots in referendum elections. In 1960 the Michigan electorate approved a constitutional amendment which: (1) changed the requirement that a constitutional convention referendum secure a majority of the vote cast in the election to a majority of votes cast on the question; (2) changed the basis for electing delegates to the convention; and (3) provided for another constitutional convention referendum in the 1961 Spring election. In April 1961, the electorate approved the proposal to call a convention. Finally, in April 1963, after a convention had met and drafted a new state constitution, the voters ratified the document. ${ }^{9}$ In this paper, I propose to examine the effect of the machine-paper ballot phenomenon on participation and the direction of the vote in the four Michigan constitutional revision referenda. The objective will be to determine whether the findings of White and Mather can be substantiated for a series of referendum elections in which the issue remains constant. If the phenomenon which they discovered is not transitory, I should find that the use of voting machines was strongly associated with a lower level of participation (i.e., there was more roll-off) than was the use of paper ballots in each of the four referenda. Similarly, there should be a relationship between the use of voting machines and an affirmative vote on the question. If their conclusions are in large part substantiated, we should also be able to lend further support to their assertion that the more extensive use of voting machines in urban areas and paper ballots in rural areas accords the latter areas an unfair advantage in referendum elections and this favors the opponents of constitutional revision.

\footnotetext{
- The drafting of the new Michigan constitution is recounted in Albert L. Sturm, Constitution-Making in Michigan, 1961-1962 (Ann Arbor: Institute of Public Administration. U. of Michigan, 1963); and in James K. Pollock, Making Michigan's New Constitution, 1961-1962 (Ann Arbor: George Whar Publishing Co., 1963).
} 


\section{METHODS}

In approaching the problem, it secmed desirable to employ a research design which would provide an additional dimension to the study of the machine-paper phenomenon and which would overcome the limitations inherent in the use of the county as the unit of analysis. The basic difficulty involved in adopting the county as the analytical unit is the lack of homogeneity between counties with respect to such variables as size, partisan tendency, and various demographic characteristics. Also, not all counties exclusively employ one type of ballot mechanism, i.e., some counties use both voting machines and paper ballots. Furthermore, the small number of counties makes it difficult to control for the confounding effects of certain variables by means of sampling techniques.

The solution to at least some of these problems seemed to lie in the use of the precinct as the unit of analysis. Then it would be possible to draw a sample from Michigan's more than 5,200 precincts which would control for certain variables. This would permit direct examination of the effect of the machine-paper phenomenon on participation and the direction of the vote. Precincts are also relatively homogeneous as compared to counties and thus we are not troubled by the prospect of gross distortion arising from treating all units as equal.

In drawing the sample, it seemed most appropriate to have a workable number of paper ballot precincts matched with an equal number of voting machine precincts. Accordingly, the objective was to develop a set of 100 paper ballot precincts matched with 100 machine precincts with respect to percent Democratic gubernatorial vote in 1960, size, urban-rural, and any other aggregate characteristics for which census information was available. ${ }^{10}$ In selecting a cross-section of precincts, Michigan's approximately 5,200 precincts were divided into 50 relatively homogeneous strata according to size, per cent Democratic gubernatorial vote in 1960, and urban-rural. However, because there were 22 strata in which there were no paper precincts there was necessarily a large pool of machine precincts which would not be the best matches for paper precincts. These strata were excluded from further consideration. This meant that while the 100 pairs of matched precincts in the sample were controlled with respect to size, partisan tendency, and urban-rural, they were not a random sample of the state's precincts. The sample would, however, permit an examination of the effect of the machine-paper phenomenon unconfounded by the effects of precinct size, partisan tendency, and urban-rural composition. The remaining 28 strata were divided into three groups: (1) predominantly machine strata in metropolitan Wayne, Oakland, and Macomb counties; (2) predominantly machine strata outstate; and (3) predominantly paper strata outstate.

Separately, the three groups were divided into machine and paper precincts. For the first two groups 38 random selections of paper precincts were made from 19 homogeneous strata. These randomly selected paper precincts were then matched with machine precincts in the group on as many census characteristics as possible. The third group was treated in the opposite way, i.e., machine precincts

${ }^{10} \mathrm{I}$ am indebted to Ralph Bisco of the University of Michigan Survey Research Center who designed and drew the sample. This description of the sample is, in large part, based on his explanation of it. 
were randomly selected from 31 strata and matched with paper precincts. Census data were obtained in urban areas from census tracts and in rural areas by using information about counties. Because of the relative homogeneity of the rural counties it seemed most probable, although there was no statistical proof, that the rural precinct estimates were as close to being accurate as the urban precinct estimates.

Conceptually, it is important to note that it is not possible to define the universe being sampled without aggregating characteristics of the two separate universes of machine and paper precincts which are most matchable. With the exception of group 3 it can only be said that we have selected a random sample of matchable precincts. Metropolitan Detroit is virtually unrepresented because it is an almost exclusively machine precinct area. For the same reason, outstate cities with a population over 40,000 are underrepresented. However, group 3 is, for all practical purposes, a random sample, self-weighting, of rural, outstate precincts.

What we are analyzing, then, is a virtual random sample of 100 pairs of matched precincts. In the matching process we have controlled for size, partisan tendency, urban-rural composition, and census characteristics, e.g., education, income, race, nativity, etc. The precincts in each matched pair have been made as nearly identical as possible with respect to these independent variables. They differ with respect to ballot mechanics, i.e., the use of either voting machines or paper ballots. This enables us to examine directly the effect of the machine-paper phenomenon on the direction of the referendum (affirmative or negative) and participation in the referendum (where participation level is defined as the proportion of votes cast in the referendum to the total votes cast for the highest state office contested on a partisan basis). It should be noted that this is not a random sample of the state's 5,200 precincts, but rather of matchable precincts.

The statistical techniques employed in the analysis are quite straightforward. Wherever appropriate and possible, Pearsonian product moment correlations will be calculated. Where the use of nominal-level variables, e.g., machine-paper, preclude calculation of Pearsonian r's, correlation ratios will be used.

ANALYsis

In working with a sample of matched analytical units such as precincts in which controls are imposed for certain variables, it is helpful to know the extent to which the controls are effective. Accordingly, validation correlations (Pearsonian r's) were calculated between machine and paper ballot precincts with respect to the percentage of Democratic vote in each election. (See Table 1.) The high

TABLE 1

Correlation Between Mean Percentage of Democratic Vote in Maghine and Paper Ballot Pregincts in Four Elections

\begin{tabular}{ccccccc}
\hline \hline & & 1958 & 1960 & 1961 & 1963 \\
\cline { 3 - 6 } & $\mathbf{r}$ & & .92 & .98 & .86 & .88 \\
\hline
\end{tabular}

coefficients obtained indicate that partisan tendency was quite effectively controlled. Predictably, the highest coefficient was for 1960, the election which served 
as the basis for matching the precincts. The other variables for which controls were established (size, urban-rural composition, and census characteristics) cannot be validated through readily obtainable data, but since they are relatively more constant there is less chance that changes in them will introduce distorting error. Interestingly, correlations between paper and machine ballot precincts with respect to support for constitutional revision in each of the four referenda were neither high nor consistent. (They ranged from .132 in 1958 to .568 in 1963). This indicates substantial variation between machine and paper ballot precincts in support for constitutional revision.

The degree to which the machine-paper phenomenon accounts for variation in support for revision could not be examined through Pearsonian correlations because machine-paper is a dichotomous nominal-level variable. However, it is possible to obtain some indication of this impact from the mean percentage of support for constitutional revision in both categories of precincts and by calculating correlation ratos $\left(\mathbf{E}^{2}\right)$. The mean percentage of support for revision was greater in machine precincts in each referendum. (See Table 2.) Since the pre-

TABLE 2

Mean Percentage of Support for Gonstitutional Revision in Machine and Paper Ballot Precincts in Four Referenda

\begin{tabular}{|c|c|c|c|c|}
\hline & 1958 & 1960 & 1961 & 1963 \\
\hline 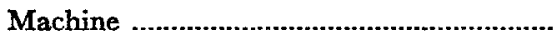 & $53 \%$ & $46 \%$ & $37 \%$ & $48 \%$ \\
\hline Paper & 48 & 42 & 31 & 45 \\
\hline 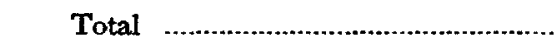 & 50 & 44 & 34 & 46 \\
\hline
\end{tabular}

cincts were matched with respect to other independent variables which might explain the variance, these data seem to suggest that the machine-paper phenomenon accounts for the difference in support for constitutional revision. The computation of correlation ratios, however, does not lend much support to this hypothesis. ${ }^{11}$ Ballot mechanics accounts for only a small proportion of the variance in support for constitutional revision (no more than 4 per cent). (See Table 3.)

TABLE 3

Correlation Ratios in Four Referenda: Control Variable, Maghine-Paper; Dependent Variable, Support for Constitutional Revision

\begin{tabular}{|c|c|c|c|c|}
\hline & 1958 & 1960 & 1961 & 1963 \\
\hline 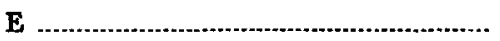 & .21 & .13 & .15 & .10 \\
\hline $\mathbf{E}^{\mathbf{2}}$ & .04 & .02 & .02 & .01 \\
\hline$F$ test $p=.05$ & $\mathbf{s}$ & ns & s & $\mathrm{ns}$ \\
\hline
\end{tabular}

Taken together, the data presented in Tables 2 and 3 indicate that although the relationship between ballot mechanics, i.e., machine-paper, and support for constitutional revision is weak, it does exist insofar as machine precincts tend to be more

\footnotetext{
${ }^{11}$ The correlation ratio of the explained to the total sum of squares. Its interpretation is analogous to that of the Pearsonian r. See Hubert M. Blalock, Social Statistics (New York: McGraw-Hill, 1960). pp. 266-67 and 297-98.
} 
supportive than paper precincts. Since controls were imposed for urban-rural composition, partisan tendency, and other independent variables, this is a rather interesting finding in spite of the absence of statistical significance at the .05 level in two of the four elections.

In examining the effect of the machine-paper phenomenon on the other dependent variable, participation levels in the four referenda, I employed similar analytical techniques. Mean participation levels in each of the four referendum elections were consistently higher in the paper ballot precincts. (See Table 4.) The ascending participation levels in both machine and paper ballot precincts may in part reflect the increased salience of the constitutional revision issue for the electorate in each successive referendum. In no election, however, did participation levels in the machine precincts reach those in the paper ballot precincts. Since the precincts were matched with respect to other major variables, the implication is that ballot mechanics, i.e., machine or paper ballot, accounted for the variation in participation levels between the two categories of precincts. Computation of correlation ratios indicates that there was in fact a fairly strong relationship between

TABLE 4

Mean Participation Levels in Maghine and Paper Ballot Precingts in Four Referenda

\begin{tabular}{|c|c|c|c|c|}
\hline & 1958 & 1960 & 1961 & 1963 \\
\hline Machine & $61 \%$ & $65 \%$ & $83 \%$ & $95 \%$ \\
\hline Paper & 87 & 87 & 99 & 105 \\
\hline Total & 74 & 76 & 92 & 100 \\
\hline
\end{tabular}

ballot mechanics and participation. (See Table 5.) In the first two referenda, the machine-paper phenomenon accounted for one-third of the variance in participation levels and slightly less than that proportion in 1961. Even in the ratification election, when referendum participation actually exceeded that in the highest partisan contest, ballot mechanics accounted for 10 per cent of the variance in participation level.

In searching for an explanation of these data, it is important to note that the first two referenda were held simultaneously with regular biennial general elections

TABLE 5

Correlation Ratios in Four Referenda: Control Variable, Machine-Paper; Dependent Variable, Participation Level*

\begin{tabular}{lrrrrrr}
\hline & & 1958 & 1960 & 1961 & 1963 \\
& & .58 & .58 & .52 & .32 \\
$\mathrm{E}^{2}$ & $\ldots$ & .33 & .27 & .10 \\
\hline
\end{tabular}

* Results significant at the .001 level using a one-tailed $\mathrm{F}$ test.

which featured contests for governor, United States senator, and, in 1960, President. Voter turnout in those elections was high, but there was a considerable rolloff in referendum participation. The 1961 and 1963 referenda, in contrast, were held simultaneously with off-year biennial Spring elections. (Incidentally, the 
Spring elections have been abolished under the new 1963 constitution.) Those elections featured partisan contests for lesser state offices such as superintendent of public instruction, highway commissioner, and members of four educational governing boards as well as a number of nonpartisan judicial offices. Turnout in Spring elections was characteristically low, usually running about one-third of the potential electorate. ${ }^{12}$ In the 1961 and 1963 referenda participation levels were higher than in the two previous elections and roll-off was much less. In high turnout elections such as 1958 and 1960, then, the machine-paper phenomenon accounted for a greater proportion of the roll-off than in the low turnout elections.

This phenomenon is no doubt due, at least in part, to the tendency of a greater proportion of voters in the low turnout, off-year elections to be highly motivated and well-informed than is the case in high turnout general elections. Consequently, proportionately fewer voters in low turnout elections are likely to neglect the opportunity to participate in the referendum or to be confused by the mechanical complexity of the voting machine. Stated alternatively, high turnout elections involve participation by a larger proportion of poorly informed voters and result in greater roll-off from partisan contests to referendum questions. ${ }^{13}$ Therefore, as referendum participation levels increase, the machine-paper phenomenon accounts for a smaller proportion of the variance in participation.

These findings also suggest that voting machines are filters which act to screen certain poorly informed voters out of referendum elections. Presumably such voters would participate if they were able to cast paper ballots. (We are not considering those voters who fail to participate because of apathy toward the referendum question.) What effect can this mechanical screening, which results from the placement of referendum questions on the voting machine, have on the outcome of referendum elections involving the issue of state constitutional revision? White and Mather both concluded that since voting machines tend to predominate in urban areas and paper ballots in rural areas, ${ }^{14}$ and since urban areas tend to be more supportive of constitutional revision, the existing distribution of machine and paper ballot voting works against affirmative referendum results. This may not necessarily be the case.

Here, we have controlled for urban-rural composition in the process of matching machine and paper ballot precincts. Machine precincts uniformly produce lower referendum participation levels. The assumption which White and Mather make regarding the effect of the machine-paper phenomenon on the direction of the referendum vote is correct only if it is true that those voters filtered out by voting machines would have supported constitutional revision. A number of recent

12 Turnout in the four elections under study followed this pattern. Defined as the proportion of the estimated number of persons of voting age who cast votes for the highest state office contested on a partisan basis, turnout fluctuated as follows: $1958,62 \% ; 1960$, $71 \% ; 1961,27 \%$; and 1963, 36\%. The Census Bureau's estimate of 4,564,000 persons of voting age in 1960 is the basis of these figures.

${ }^{13}$ This reasoning draws support from Clarence Stone's conclusion that low turnout referenda consist mainly of votes cast by "civic activists" whereas high turnout referenda involve participation by poorly informed "inactivists." See "Local Referendums: An Alternative to the Alienated Voter Model," Public Opinion Quarterly, 29 (1965), 213-22.

14 The problems encountered in drawing the sample of matched precincts employed in this study confirmed their assumption in this regard. 
studies of local referenda have produced findings to the contrary. Using individual data obtained through surveys, studies of school bond, metropolitan area government, and fluoridation referenda conclude that negative voting is a manifestation of political alienation which is highest among low status voters, and as turnout rises so does the proportion of negative votes. ${ }^{15}$ Of particular relevance here because of the similarity of the issue, is the finding of McDill and Ridley that low status, anomie, and political alienation were significantly related to a negative vote and an unfavorable attitude on the issue of metropolitan government in Nashville, Tennessee. ${ }^{16}$ It may well be that the use of voting machines removes more potential negative than affirmative voters from referendum elections. Unfortunately survey data could not be obtained to examine this possibility in the four Michigan constitutional revision referenda. It seems, however, that there is as much if not more basis for assuming that voting machines aided rather than hampered the cause of constitutional revision in Michigan. This was probably even more so in the 1963 ratification referendum when the Democratic party actively opposed the proposed constitution and support for it in the Detroit metropolitan area dropped considerably. In that election, support for constitutional revision in outstate areas tended to be much higher than it had been in any of the three previous referenda. ${ }^{17}$ Voting machines may have kept potential negative voters out of the referendum in the metropolitan area. These voters would, because of their strong Democratic identification, have followed the party's stand on the proposed constitution. At the same time, paper ballot precincts in predominantly rural areas were more supportive of constitutional revision than they had been in the past. In those areas paper ballots were admitting fewer than the usual number of outstate negative voters.

Explanations such as these are necessarily speculative. The questions which they raise such as the attitudes of voters failing to participate in the referenda although casting votes in partisan contests for office can be answered only through individual data. The aggregate data and ecological correlations presented here, even though for a sizable number of small relatively homogeneous analytical units,

${ }^{15}$ See J. E. Horton and W. E. Thompson, "Powerlessness and Political Negativism: A study of Defeated Local Referendums," American Journal of Sociology, 47 (March 1962), 485-93; E. L. McDill and J. C. Ridley, "Status, Anomie, Political Alienation and Political Participation," American Journal of Sociology, 48 (September 1962), 205-13; Arnold Simmel, "A Signpost for Research on Fluoridation Conflicts: The Concept of Relative Deprivation," Journal of Social Issues, 17 (1961), 26-36; and, William A Gamson, "The Fluoridation Dialogue: Is It an Ideological Conflict?" Public Opinion Quarterly, 25 (1961), 526-37. However, cf. Stone, op. cit., and James Q. Wilson and Edward C. Banfield, "Public Regardingness as a Value Premise in Voting Behavior," American Political Science Review, 58 (1964), 876-87. Although not directly concerned with the relationship of political alienation to negativism, Wilson and Banfield have found through studying referendum elections in several cities that higher income voters tend to be more public-regarding and to manifest less narrow self-interest than low income voters. This suggests that low status voters will adopt an affirmative stance in a referendum only if it is in their interest to do so.

${ }^{16}$ McDill and Ridley, ibid., p. 205.

${ }^{17}$ Partisan stands in the first three referenda are summarized in Sturm, op. cit., pp. 17-28. In another paper, I show that partisanship did not significantly affect the results of the first three referenda, but that it was of major importance in the ratification contest. See "The Electorate and State Constitutional Revision: An Analysis of Four Michigan Referenda," Midwest Journal of Political Science, 12 (1968), 115-29. 
does not provide a basis for generalizing about specific motivational and other factors governing the behavior of individual voters. ${ }^{18}$ What has been done is to suggest probable explanations of the phenomena observed in the data.

\section{Conclusion}

The most salient finding which emerges from this analysis is the strong relationship of the machine-paper phenomenon to participation levels in the four Michigan constitutional revision referenda. This confirmed through different analytical techniques the previous findings of White and Mather that the use of voting machines results in lower referendum participation levels than does the use of paper ballots. The fact that this relationship persisted in the presence of controls for what seemed to be other potentially significant variables - partisan tendency, urban-rural composition, and census characteristics - should help to clarify its nature. It seems fairly apparent that the more complex mental and physical actions required to cast a referendum vote on a voting machine rather than on a paper ballot prevent certain voters from participating when machines are used. I have suggested, on the basis of local referendum studies which have used survey data, that such voters probably tend to be apathetic, poorly-informed, of low socioeconomic status, and potentially inclined toward a negative position with respect to the issue.

The exclusion of these and other voters from referendum elections through the filtering action of mechanical voting devices is an empirical phenomenon. How one reacts to it is a normative question. On the one hand it can be argued that the roll-off of such persons ought not to be of great concern since they are ill-equipped to make the complex choices which referendum proposals often force on the voter. Furthermore, their alienation induces negativism and this unduly biases the result on wholly nonrational grounds. On the other hand, a strong case can be made that a democratic society requires the participation of all of its citizens on an equal basis. Any factor which works against this goal, such as the machine-paper phenomenon, by placing citizens on an unequal basis is undemocratic and ought to be corrected.

Without attempting to explore the assumptions underlying these positions, I would suggest that most of the problems raised by differential ballot mechanics can be resolved through the adoption of a uniform ballot mechanism. This means either all machine voting or all paper ballot voting within a state. The difficulties of such standardization are not insurmountable. State assistance may be required to enable local jurisdictions to purchase voting machines and to provide more effective instruction in their use. In heavily populated states opting for paper ballots, counting problems can be eased through the use of electronic counting equipment and special ballot-marking devices.

\footnotetext{
${ }^{18}$ The potential fallacy of generalizing about individual-level phenomena on the basis of ecological correlations has been spelled out in W. S. Robinson, "Ecological Correlation and the Behavior of Individuals," American Sociological Review, 15 (1950), 351-57. However, cf. Austin Ranney, "The Utility and Limitations of Aggregate Data in the Study of Electoral Behavior," in Austin Ranney (ed.), Essays on the Behavioral Study of Politics (Urbana: U. of Illinois Press, 1962), pp. 91-102.
} 
It is not my purpose to argue on behalf of voting machines or paper ballots. What does seem necessary, however, is a uniform ballot, machine or paper, in each state. The practice of using both machines and paper ballots in a single state distorts the operation of the electoral system by not making the actual physical act of voting an identical experience for all voters. This enhances the interests of some individuals and groups at the expense of others and is, in the context of my own normative criteria of a democratic society, undesirable.

Initially I had hoped to uncover evidence of the effect of the machine-paper phenomenon on the direction of the vote in the four constitutional revision referenda. The analysis was inconclusive on this point. At first it appeared that since machine precincts were more supportive of revision and exhibited lower participation levels than paper ballot precincts, the machine-paper phenomenon worked against revision. Correlation ratios in the four campaigns indicated, however, that very little of the variance in support for constitutional revision could be explained by the mechanics of the ballot. Furthermore, it seemed at least probable on the basis of other studies which related alienation, low status, and lack of education to negativism in local referenda that voters screened out of referendum elections by voting machines would have tended to vote against constitutional revision.

These data do not resolve the basic question. The earlier studies of White and Mather assume that those voters kept from participating in the referenda by voting machines would have divided in the same proportions as those who did vote. $\mathrm{My}$ alternative hypothesis suggests that those screened out by machines because of low educational level, etc., would have voted negatively regardless of where they lived. Furthermore, my hypothesis assumes that many low status, politically alienated voters who did vote in paper ballot precincts and who would not have voted in machine precincts were negative voters. In all likelihood the truth lies somewhere between these two alternatives which constitute, in a sense, the ends of a continuum.

Further exploration of the effects of the mechanical aspects of the ballot on individual voting behavior seems required if firm answers to some of the questions raised here are to be found. It is, in my judgment, doubtful that further explorations using aggregate data will be very rewarding. A more promising approach would be to obtain survey data both prior to and immediately following statewide referendum elections. Such studies should, if possible, be conducted in states with varying voting mechanisms, e.g., all machine, all paper ballot, and a mixture of the two. Another useful avenue of inquiry might be through an experiment using a sample of respondents, e.g., high school students, with varying socio-economic backgrounds. In any event, explanations of the effect of ballot mechanics, which in itself is a highly interesting phenomenon, must await the conduct of studies based on individual data. 